\title{
Causes and consequences of sleepiness among college students
}

\author{
This article was published in the following Dove Press journal: \\ Nature and Science of Sleep \\ 23 June 2014 \\ Number of times this article has been viewed
}

\section{Shelley D Hershner \\ Ronald D Chervin}

Department of Neurology, University of Michigan, Ann Arbor, MI, USA
Correspondence: Shelley D Hershner Department of Neurology, University of Michigan, Med Inn C728, 1500 East Medical Center Drive, Ann Arbor, MI, USA

Tel +l 7349366295

Fax +I 7346479065

Email shershnr@umich.edu
Abstract: Daytime sleepiness, sleep deprivation, and irregular sleep schedules are highly prevalent among college students, as 50\% report daytime sleepiness and $70 \%$ attain insufficient sleep. The consequences of sleep deprivation and daytime sleepiness are especially problematic to college students and can result in lower grade point averages, increased risk of academic failure, compromised learning, impaired mood, and increased risk of motor vehicle accidents. This article reviews the current prevalence of sleepiness and sleep deprivation among college students, contributing factors for sleep deprivation, and the role of sleep in learning and memory. The impact of sleep and sleep disorders on academics, grade point average, driving, and mood will be examined. Most importantly, effective and viable interventions to decrease sleepiness and sleep deprivation through sleep education classes, online programs, encouragement of naps, and adjustment of class time will be reviewed. This paper highlights that addressing sleep issues, which are not often considered as a risk factor for depression and academic failure, should be encouraged. Promotion of university and college policies and class schedules that encourage healthy and adequate sleep could have a significant impact on the sleep, learning, and health of college students. Future research to investigate effective and feasible interventions, which disseminate both sleep knowledge and encouragement of healthy sleep habits to college students in a time and cost effective manner, is a priority.

Keywords: grade point average, GPA, sleep deprivation, academic performance, adolescence, sleep education programs

\section{Introduction}

The college experience is of great value in providing emerging adults with a structured environment in which they can gain the knowledge, skills, and independence to chart their own path, become successfully employed, and contribute to society. However, this experience comes at great cost given rising tuition fees and ballooning student debt, and thus, it is vital that the college years be as efficacious as possible. A potential obstacle to maximizing success in college is the high prevalence of daytime sleepiness, sleep deprivation, and irregular sleep schedules among college students.

Daytime sleepiness is a major problem, exhibited by $50 \%$ of college students compared to $36 \%$ of adolescents and adults. ${ }^{1}$ At least 3 days a week, $60 \%$ of students report that they are dragging, tired, or sleepy. ${ }^{2}$ Sleepiness is defined as the inability or difficulty in maintaining alertness during the major wake period of the day, resulting in unintended lapses into drowsiness or sleep. ${ }^{3}$ It is important to note that sleepiness is often circumstance-dependent, with many aspects of the students' learning environment exacerbating sleepiness. ${ }^{4}$ For example, a lecture that does not require active 
participation and may be in a dark, warm lecture hall can unmask underlying sleepiness. Sleep deprivation is defined as obtaining inadequate sleep to support adequate daytime alertness. ${ }^{4}$ How much sleep a young adult needs is not clearly known, but is thought to be 8 hours. ${ }^{5,6}$ Most college students are sleep deprived, as $70.6 \%$ of students report obtaining less than 8 hours of sleep. ${ }^{7}$ The impact of educational major on sleepiness and sleep duration is not well studied, but the effect may be substantial. As reported at an Architecture School in the Midwest, only $4 \%$ of students obtained at least 7 hours of sleep at night; the average sleep duration was 5.7 hours, with 2.7 "all-nighters" per month. ${ }^{8}$ Eighty-two percent of college students believe that inadequate sleep and sleepiness impact their school performance. ${ }^{9}$ Students rank sleep problems second only to stress in factors that negatively impact academic performance. ${ }^{10}$

Sleep deprivation and sleepiness are caused by a host of reasons and have numerous negative consequences. In the literature, sleep deprivation is often termed either acute sleep deprivation or chronic partial sleep deprivation. Colloquially for students, acute sleep deprivation is termed "pulling an all-nighter", meaning that a person stays up for 24 hours or longer. More typically, sleep deprivation consists of chronic partial sleep deprivation, where a student obtains some, but not adequate sleep. Sleepiness can be an obvious consequence of sleep deprivation, but sleepiness can be caused by other circumstances, most commonly sleep disorders. To understand the consequences of sleepiness and sleep deprivation, knowledge of normal sleep and its impact on learning, memory, and performance are necessary. Equally important are potential interventions, as these may offer an opportunity to improve health and educational outcomes for this demographic. This article reviews the prevalence of sleepiness and sleep deprivation among college students, the impact of sleep on memory, contributing factors for sleep deprivation, potential consequences with a focus on those particularly applicable to college students, and available interventions to improve sleep among college students.

\section{Regulation of normal sleep: the circadian rhythm and homeostatic sleep drive}

Many college students are sleep deprived because they go to sleep late and wake up for classes or employment before adequate sleep is obtained. Two primary processes govern how much sleep is obtained, the homeostatic sleep drive and the circadian rhythm. The circadian system (internal clock) helps to regulate sleep/wake cycles and hormonal secretions while the homeostatic sleep drive increases the need for sleep as the period of wakefulness lengthens. The interaction of these two systems is described by the Two-Process Model of Sleep Regulation. $^{11}$

Physiologically, adolescents and young adults tend to have a delayed circadian preference, and are "night owls". ${ }^{12}$ This change occurs in association with puberty; more physically mature adolescents have a preference for later bedtimes and may have a lower homeostatic sleep drive, and consequently, are less sleepy at night. ${ }^{13-15}$ The typical adult circadian period is 24.1 hours, compared to an adolescent's circadian period of 24.27 hours; this longer period makes it easier for the bedtime to shift later. ${ }^{15,16} \mathrm{~A}$ cardinal sign of a delayed circadian system is an irregular sleep schedule, where students have catch-up sleep on the weekend. Both high school and college students demonstrate a 1-3 hour sleep deficit on school nights, with a much longer sleep duration and often a later wake time on the weekends. ${ }^{7,17,18}$

How the circadian rhythm and homeostatic sleep drive change with puberty is not well understood, but the cumulative effect is that adolescents and young adults feel more awake in the evening, have a difficult time falling asleep until later, and consequently, have insufficient sleep during the school week and catch-up on sleep on the weekend.

Exactly when this nocturnal preference or "night owl" tendency diminishes, remains unclear. When evaluated longitudinally, weekday bedtimes continued to delay until around 19 years of age, with weekend bedtimes remaining later until the early 20 s, although other studies have shown this delay persisting until the junior year. ${ }^{19}$ The transition from high school to college also has an impact; college students go to bed 75 minutes later than high school students. ${ }^{7}$ In this study, freshman students' bedtime was 12.22 am and 1.58 am with a rise time of 8.08 am and 10.26 am on weekdays and the weekend, respectively.

\section{Learning, memory, and sleep cycles}

Sleepiness and irregular sleep schedules have many unintended consequences, one of which is to negatively impact learning, memory, and performance. The precise details of the relationship between sleep and memory formation are not yet completely understood. The dual process theory maintains that certain types of memory are dependent on specific sleep states, such that procedural memory (knowing how) may be dependent on REM (rapid eye movement) sleep and declarative memory (knowing what) on NREM (non-REM) sleep. The sequential processing theory suggests that memories require an orderly succession of sleep stages, 
ie, memory formation may be prompted by slow-wave sleep and consolidated by REM sleep (see Figure 1). ${ }^{20}$

Both theories may help to explain how a student's sleep pattern could impact learning. ${ }^{21}$ In one study, REM sleep deprivation eliminated sleep-induced improvement on a visual perceptual learning (procedural) task; the same effect was not found with selective slow-wave sleep deprivation. ${ }^{22}$ REM sleep normally occurs every 90-120 minutes, approximately 4-5 times in a typical night, with each REM sleep period growing progressively longer, with the last episode near rise time. ${ }^{23}$ Therefore, college students with early morning classes may not attain the last 1-2 REM sleep periods, thus adversely affecting procedural memory. However, other studies suggest that NREM rather than REM sleep enhances procedural memories, while other studies correlated improvement with slow-wave sleep followed by REM sleep. ${ }^{24-26}$ Both of these theories support that sleep deprivation may limit the amount of REM sleep and/or slowwave sleep that students obtain, which may compromise both learning and memory, but further research is required to clarify this.

Many studies investigating the interaction of sleep, memory, and learning use scenarios of a specific memory task and then alter subjects' sleep pattern or duration to determine the impact that sleep had on the subject's performance. These scenarios often may not directly correlate with the memory and learning that college students are expected to perform or the alterations in their sleep schedule they experience. Despite

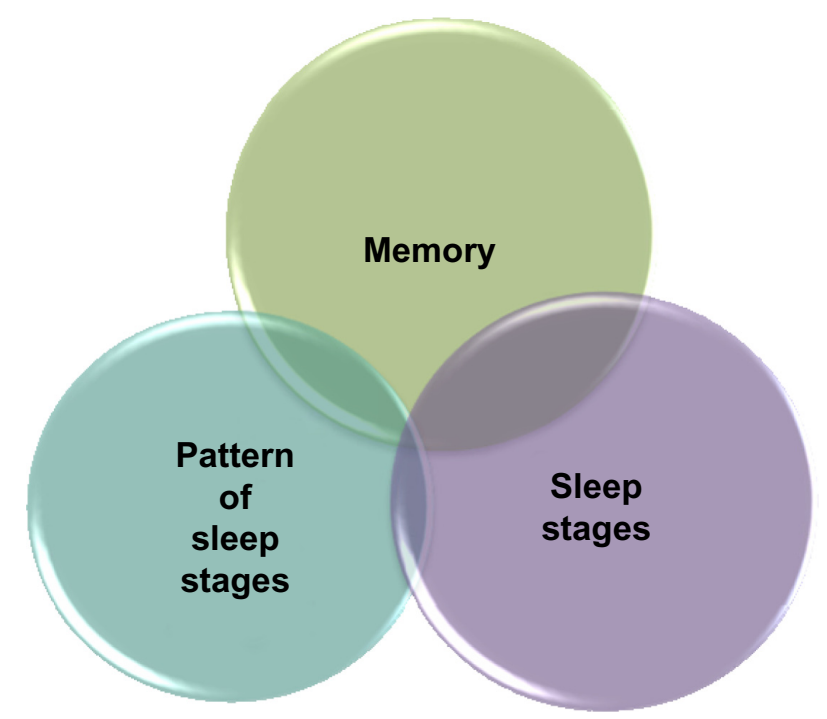

Figure I The interaction of sleep and memory.

Notes: The dual process theory suggests that certain types of memory are dependent on specific sleep states, such as REM sleep, or slow-wave sleep (a stage of NREM sleep). The sequential processing theory suggests that memories require an orderly succession of sleep stages, eg, slow-wave sleep followed by REM sleep. ${ }^{20}$ Abbreviations: NREM, non-rapid eye movement; REM, rapid eye movement. these limitations, these studies illuminate the impact of sleep on students' memory, learning, and potential academic performance.

Some students may "pull an all-nighter" (24 hours or more of sleep deprivation) before examinations in the hope of improved grades. The literature suggests that all-night study sessions are the wrong plan for improved grades and learning. Subjects were taught a visual discrimination task to identify the presence of " $T$ " or " $L$ " and the orientation of three diagonal bars on a screen. Subjects who were sleep deprived for 30 hours showed no improvement in performance, even after 2 days of post-recovery sleep. ${ }^{26}$ Non-sleep-deprived subjects' performance improved for the next 4 days. In another study investigating if improvement correlated with time or time spent in sleep, subjects were taught a motor task and then tested either after a 12-hour period of wakefulness or a 12-hour period that included sleep. ${ }^{24}$ Subjects tested at 10 am and then retested at 10 pm without sleep showed no significant change in performance. After a night of sleep, subjects' performance improved by $18 \%$. Subjects tested at $10 \mathrm{pm}$ initially, then retested after sleep, also had a significant improvement in performance. This supports the concept that sleep, and not just time, is required for learning and memory consolidation. It may be possible that there is a window for potential learning that requires sleep, and that this opportunity for learning may not be salvaged even after sleep is recovered.

Sleep before learning may also be necessary. To investigate this concept, subjects were tested on an episodic memory encoding task, which involved viewing a series of images with a recognition test 48 hours later. ${ }^{27}$ Subjects were tested after 35 hours of sleep deprivation; memory performance was approximately two letter grades $(19 \% ; P=0.031)$ worse when compared to the non-sleep-deprived subjects. This difference did not seem to be due to alertness, as there was no significant difference between the two groups in terms of response rate, which has been correlated with alertness.

Looking at more global functions, total sleep deprivation showed a significant decrease of performance in cognitive tasks assessing inference, recognition of assumptions, and deduction. ${ }^{28}$ Although this study was not carried out on college-aged students, subjects aged 10-14 years of age restricted to 5 hours of sleep, had impaired performance on verbal creativity and abstract thinking. ${ }^{29}$ Less complex cognitive functions did not appear impaired; this has been shown in other studies and may indicate that motivation, individual response to sleep deprivation, or certain tasks may be less impacted by sleep. ${ }^{20,30}$ 
Learning may also affect the intrinsic aspects of sleep. Procedural tasks prior to sleep increased slow-wave activity in the right parietal lobe, an area that is responsible for visualspatial skills. ${ }^{31}$ This increased right parietal activity correlated with improvement in the task. Other studies have found an increase in spindles, a defining feature of stage 2 sleep, after procedural memory training. ${ }^{32}$ In an intensive 6-week French language immersion course, improvement was correlated with an increase in subjects' percentage of REM sleep. ${ }^{33}$

In summary, these finding suggest that sleep, likely before and after specific memory tasks, plays an integral part in memory consolidation. Many of these studies isolate memory into specific areas such as visual, declarative, or procedural; however, college students' learning, memory, and performance in classes rarely would have such a narrow memory domain. Further research with real-life circumstances of students would better help clarify these important issues.

\section{Causes of sleep deprivation and sleepiness}

Among college-aged students, one of the most common causes of daytime sleepiness is sleep deprivation, ie, students get inadequate sleep because they go to bed late and wake up early. This occurs for multiple reasons; some are physiologic and others behavioral. The behavioral components may be particularly problematic on college campuses. However, sleep deprivation is not the only cause of sleepiness as college students are not immune to sleep disorders, which may also cause sleepiness. This section will review common causes of sleep deprivation as well as the prevalence of sleep disorders among college students, and the influence of sleep disorders on sleepiness.

\section{Inadequate sleep hygiene}

Sleep deprivation can arise from poor sleep behaviors; sleep hygiene encourages habits conducive to restorative sleep and avoidance of substances or behaviors that are not. Good sleep hygiene includes a regular sleep-wake schedule, quiet sleep environment, and avoidance of caffeine after lunch and stimulating activities before bed. ${ }^{34,35}$ Substances are not the only aspect of inadequate sleep hygiene, as the ubiquitous use of technology before bed may also adversely affect sleep. Many students have inadequate sleep hygiene that, in conjunction with their delayed circadian rhythm, encourages sleep deprivation.

\section{Alcohol}

Approximately four out of five college students drink alcohol, with nearly $40 \%$ of men and women reporting "binge drinking" at least 4-5 drinks in a row within the last 14 days. ${ }^{36,37}$ Alcohol shortens sleep latency, but then promotes fragmented sleep in the latter half of the night. ${ }^{23}$ One study found that $11.6 \%$ of students who drank used alcohol as a sleep aid. ${ }^{7,38}$ Alcohol may also increase the risk for obstructive sleep apnea. ${ }^{39}$

\section{Caffeine and energy drinks}

Caffeine, equivalent to 2-4 cups of coffee taken at night, can increase sleep latency on average from 6.3 to 12.1 minutes, reduce sleepiness, and improve the ability to sustain wakefulness. ${ }^{40}$ In this study, the effects of caffeine lasted 5.5-7.5 hours, suggesting that caffeine consumed even in the afternoon could impair the ability to fall asleep. Caffeine is an adenosine receptor antagonist and can increase arousal. Caffeine also may act on gamma-aminobutyric acid neurons of the posterior hypothalamus to suppress sleeppromoting pathways. ${ }^{23}$ The net effect is that caffeine increases vigilance, alertness, and decreases sleepiness.

Energy drinks are becoming increasingly popular and $34 \%$ of 18-24-year-olds consume them regularly. In 2006, Americans spent more than $\$ 3.2$ billion on energy drinks. ${ }^{41}$ The majority (67\%) of users consumed energy drinks to help compensate for insufficient sleep. ${ }^{42}$ The contents of energy drinks are variable and depend on the individual product, but usually contain caffeine, herbal products, and sometimes vitamins and other supplements. Caffeine is the primary constituent responsible for the effect of increased energy. The amount of caffeine varies widely from $45-500 \mathrm{mg}$. Use of energy drinks is associated with higher use of alcohol and possibly other drugs, including stimulants. ${ }^{43}$

\section{Stimulants}

Use of either prescribed or nonprescribed stimulants is a growing problem in young adults. The most commonly reported reason is to "stay awake to study" or increase concentration. ${ }^{44}$ Students may utilize these drugs more than age-matched non-students. ${ }^{45}$ A survey at 119 colleges and universities across the US found a $6.9 \%$ lifetime prevalence for the use of stimulants. ${ }^{46}$ Other studies show prevalence as high as $14 \% .{ }^{44,47}$ Men are more likely than women to use stimulants, as well as caffeine and energy drinks. Nonprescribed use of stimulants is associated with increased use of alcohol, cocaine, and marijuana. ${ }^{46}$ Not all stimulant use is illicit, as between $2 \%-8 \%$ of college students' self-reported symptoms are consistent with attention deficit hyperactivity disorder (ADHD).$^{48}$ However, when parents of college students were asked to report such symptoms in their 
children, the prevalence of ADHD decreased to around $1 \%$. Stimulants increase sleep latency and suppress REM sleep; subjects who use stimulant medications report worse sleep quality. $^{23,47}$

\section{Technology}

Inadequate sleep hygiene also encompasses the use of technology prior to bed. Relevant data often must be extrapolated from literature on adolescents, as few studies have focused on college students. The 2011 Sleep in America Poll addressed technology available in the bedroom. "Generation Y'ers" (adults aged 19-29 years old) are heavy users of technology prior to bed: $67 \%$ use cell phones, $43 \%$ music devices, $60 \%$ computers, and $18 \%$ video games. The majority (51\%) report rarely getting a good night's sleep and often wake unrefreshed. Computer use in the hour before bed is associated with less restful sleep, higher Epworth Sleepiness Scales, and drowsy driving. ${ }^{49}$ Frequent use of cell phones around bedtime is associated with difficulties falling asleep, repeated awakenings, or waking up too early. ${ }^{50}$ Most young adults $(57 \%)$ leave their phone on during sleep, with only $33 \%$ turning it to silent or vibrate modes (Table 1). Playing video games before bed can increase sleep latency, an average of 21.6 minutes. ${ }^{51}$ Functional magnetic resonance imaging (fMRI) shows that video game playing heightens cognitive alertness, especially during violent scenes (Table 1). ${ }^{52}$

Light exposure from various sources, including computers, tablet computers (eg, iPads; Apple Inc., Cupertino, CA, USA), and cell phones may also impact sleep. Melatonin, secreted by the pineal gland, helps regulate the circadian rhythm to the environment. ${ }^{15}$ Normally, it is low or absent during the day and starts to rise about 2 hours before the habitual bedtime. Melatonin is suppressed by light, and light sources as low 200-300 lux (room lights) can cause suppression. ${ }^{53}$ The amount of light from technologic devices

Table I Frequent use of technology before bed is associated with sleep difficulties and daytime sleepiness

\begin{tabular}{ll}
\hline Use of cell phone in the bedroom was & - Daytime sleepiness \\
associated with a higher frequency of & - Poor quality sleep \\
& - Waking unrefreshed \\
& - More difficulties falling \\
& asleep and staying asleep \\
& - Repeated awakenings \\
Use of the computer before bed was & - Drowsy driving \\
associated with a higher frequency of & - Daytime sleepiness \\
Use of video games before bed was & - Less restful sleep \\
associated with a higher frequency of & \\
\hline Note: Data from National Sleep Foundation; ${ }^{49}$ Dworak et al. ${ }^{51}$
\end{tabular}

is variable; for example, a tablet computer generated 50 lux suppressed melatonin in a cohort of college students after 2 hours of use. ${ }^{54}$ A case report describes a student in Brazil who had a 40-minute delay in sleep on the weekends when electric lights were installed. ${ }^{55}$ Bright light (8,000 lux) given at $7 \mathrm{pm}$ or at $9 \mathrm{pm}$ reduced nighttime sleepiness in students who had an evening preference and those with a later onset of melatonin. ${ }^{56}$ One of the effects of technology may be to suppress melatonin, resulting in a delay in sleep onset.

In summary, many students engage in behaviors, such as those described above, which increase stimulation and alertness prior to bed. This, in conjunction with their delayed circadian rhythm, encourages late bedtimes and insufficient sleep. To combat sleepiness, students often drink caffeine and energy drinks, compromising sleep and ensuring a vicious cycle of sleep deprivation (Table 2).

\section{Sleep disorders}

Sleep deprivation is not the only cause of sleepiness on campus, as sleep disorders may also play a role. A survey of 1,845 students in introductory psychology labs suggested that $27 \%$ were at risk for at least one sleep disorder or sleeprelated problem, including obstructive sleep apnea (4\%), insomnia (12\%), restless legs disorder and periodic limb movement disorder (8\%), circadian rhythm sleep disorders $(7 \%)$, and hypersomnia $(4 \%) .{ }^{57}$

Obstructive sleep apnea can be associated with significant sleepiness. ${ }^{58}$ The prevalence of snoring may be more common than expected, as $30 \%$ of non-overweight students in a California school reported snoring. Men more commonly reported snoring (42\%) than women $(25 \%) .{ }^{59}$ Asian students (37\%) more often reported snoring than African-American (24\%) or Caucasian (27\%) students. Although such observations of snoring frequency do not reveal the prevalence of obstructive sleep apnea among college students, they do

Table 2 Challenges to good sleep hygiene in college students

\section{Technology}

TV, computer, or video games before bed

Cell phones on overnight

Frequent exposure to light before bed

Substances

Caffeine and energy drinks

Alcohol use

Stimulant use

College scheduling and activities

Variable class schedules from day to day

Late night socializing

Early or late obligations

Note: Data from. ${ }^{41,43,47,49,54}$ 
suggest that this disorder may not be as infrequent among young, otherwise healthy college students as is sometimes assumed.

\section{Consequences of sleep deprivation and sleepiness}

College is a time of intellectual growth and development as young adults' transition from adolescence to adulthood. Although the worth of college in terms of increased productivity and higher earning potential is rarely debated, there is a significant personal and societal cost of college both in terms of time and money. For optimal return on the investment of time, effort, and money, students need to maximize their learning, academic, and personal growth. Sleepiness from any cause can compromise these goals, through impact on learning, memory, grades, perception of effort, driving performance, and mood. Although sleep deprivation has effects on many aspects of health, this article will focus on areas that may be particularly problematic for college students.

\section{Grade point average (GPA) and academic performance}

Despite growing evidence of the relationships between sleep, learning, and memory, a direct connection between learning and GPA has not yet been established. ${ }^{60} \mathrm{~A}$ student's GPA is not just an indication of learning, but instead involves a complex interaction between the student and their environment. ${ }^{61}$ Intelligence, motivation, work ethic, personality, socioeconomic status, health problems, current and past school systems, course load, academic program, and test-taking abilities all may influence GPA.

Existing evidence does suggest an association between sleep and GPA. Students who obtained more sleep (long sleepers, $\geq 9$ hours) had higher GPAs than short sleepers ( $\leq 6$ hours): GPAs were 3.24 vs 2.74 on average, respectively. ${ }^{62}$ More evidence exists to support an influence of sleep patterns rather than sleep duration on GPA. Students at a community college near Washington DC showed no difference in total sleep time (TST), sleepiness, or morning preference between high (GPA >3.5) and low (GPA <2.7) academic performers. ${ }^{63}$ High academic performers instead showed earlier bed and rise times, though with similar overall TST. No difference was present between the two groups with regards to a morning preference, but a validated questionnaire was not used.

Among first-year university students, sleep patterns also influenced GPA; each hour delay in weekday or weekend rise time decreased the GPA by $0.132 / 4.0$ and $0.115 / 4.0$, respectively. ${ }^{60}$ Bedtimes were also influential, with later bedtimes associated with lower GPAs. TST or circadian factors were not evaluated. These results do not explain why an earlier rise time was associated with better grades; it could arise from the sleep schedule itself, but many potential confounders exist. For example, early risers may also be more motivated or organized. Another possibility is that negative influences arise when students who have a nocturnal preference are unable to wake up earlier. In a study of medical students, subjects with an evening preference on the HorneOstberg Questionnaire had a more irregular sleep pattern than students with a morning or indifferent-type preference. Sleep duration was not different between the groups, but subjects with a more irregular sleep pattern had lower academic performance. ${ }^{64}$ This suggests that sleep patterns influence academic performance more than sleep duration, with the caveat that students who have an evening preference may have a more irregular sleep schedule.

Extreme forms of irregular sleep schedules include allnight study sessions. No literature appears to address the association between all-nighter study sessions and GPA, but the absence of sleep is known to affect learning and performance improvement. Subjects taught a visual discrimination task who were then sleep deprived for 30 hours showed no improvement in the task, even after 2 days of post-recovery sleep. ${ }^{26}$ Non-sleep-deprived subjects' performance improved for the next 4 days. Similar results were demonstrated with a finger-tapping motor task; without sleep, no significant improvement occurred. ${ }^{24}$ All-nighter study sessions may also alter motivation and perceived effort. Students' self-perceived effort and performance were evaluated following two sleep scenarios: 24 hours of sleep deprivation or 8 hours of sleep. ${ }^{28}$ Despite performing worse, sleep-deprived subjects felt they had better concentration, effort, and performance than did non-sleep-deprived subjects. Why sleep-deprived subjects rated their effort as higher is not known, and could be due to sleep deprivation itself, or relate to other unknown factors. This perception of improved performance following sleep deprivation may in part explain why it can be challenging to get students to change their sleep behavior. If students perceive no impairment in performance due to lack of sleep, they have little motivation to change.

\section{Sleep disorders and academic performance}

Students with sleep disorders probably do not achieve optimal academic performance, and up to $27 \%$ of students may be at risk for at least one sleep disorder. ${ }^{57}$ Students at risk for 
academic failure (GPA <2.0) were at a disproportionately high risk for sleep disorders. Among those who screened positive for obstructive sleep apnea, 30\% were at risk for academic failure. Medical students classified as frequent snorers more frequently failed their Internal Medicine examination (47\%) than did occasional snorers $(22.2 \%)$ or non-snorers $(12.8 \%)$. After adjustment for age, BMI, and sex, the relative risk for snorers to fail the examination was $1.26(95 \%$ confidence interval: $1.01-1.57) .{ }^{65}$ Obstructive sleep apnea is suspected to have cognitive effects in both children and adults. ${ }^{66}$ A higher percentage of students at risk for academic failure screened positive for other sleep disorders including: periodic limb movement disorder/restless legs syndrome $(21 \%),{ }^{67}$ insomnia (22\%), circadian rhythm sleep disorders (26\%), and hypersomnia $(21 \%) .{ }^{57}$ As nearly one in four students is at risk for a sleep disorder, screening for sleep disorders among students with poor academic performance may well be advisable.

Although many students have a nocturnal preference, this preference can progress to delayed sleep-phase disorder (DSPD), a circadian rhythm disorder characterized by sleeponset insomnia and difficulty waking at the desired time. ${ }^{3}$ Consequences of DSPD may include missed morning classes, increased sleepiness, and decreased concentration, especially in morning classes. Students with DSPD have lower grades. ${ }^{68}$ The prevalence of DSPD in the US college population may be as high as $6.7 \%-17 \%{ }^{68,69}$

\section{Driving}

One of the most concerning consequences of sleep deprivation and sleepiness is drowsy driving. In the 2011 Sleep in America Poll, 66\% of young adults reported drowsy driving. ${ }^{49}$ However, few studies have evaluated drowsy driving specifically in college students. Among 1,039 undergraduate students, $16 \%$ reported falling asleep while driving and $2 \%$ had had a motor vehicle accident due to sleepiness. Men were more likely to fall asleep while driving than women. ${ }^{38}$ A school in Utah had 86 student deaths due to motor vehicle accidents over a 15-year period; dozing/ sleepiness was thought to be causative in $44 \%-72 \%$ of the cases. In a retrospective review of students" "closest calls" for a motor vehicle accident due to sleepiness, most near accidents occurred between $11 \mathrm{pm}$ and 1 am and often (39\%) during the first hour of driving. Nearly half $(48 \%)$ of students had a less intense dozing episode earlier in the same drive, with $68 \%$ of students continuing their drive despite feeling sleepy. ${ }^{70}$ The findings overall suggest that drowsy driving accidents or near accidents are too frequent and that students may minimize the warning signs of drowsiness.

\section{Driving, sleep deprivation, and alcohol}

The impact of sustained wakefulness on driving performance has been compared to the impairment of performance that is produced by specific blood alcohol levels. In adults, sustained wakefulness of 17 hours was equivalent to a blood alcohol concentration (BAC) of $0.05 \%$, and 24 hours was equivalent to $0.1 \%$, above the legal level for intoxication in the US and most countries worldwide. ${ }^{71,72}$ Similar findings were found in males aged 19-35 years of age, in whom 18.5 and 21 hours of wakefulness produced changes in driving performance mimicking a $0.08 \%$ BAC. ${ }^{73}$ Sleep deprivation in combination with alcohol has a synergistic detrimental effect on driving performance. To evaluate these effects, young male college students were sleep restricted to 4 hours in bed; they then consumed alcohol until they attained BACs of $0.025 \mathrm{~g} / \mathrm{dL}$ or $0.035 \mathrm{~g} / \mathrm{dL}$, equivalent to about $1-2$ drinks. ${ }^{74}$ A simulated driving task at 2 pm monitored crashes, speed variability, and lane deviations. Crashes occurred in $23 \%$ and $33 \%$ of the subjects (BAC $0.025 \mathrm{~g} / \mathrm{dL}$ and $0.035 \mathrm{~g} / \mathrm{dL}$, respectively), compared to only $4.7 \%$ in the controls and $19 \%$ in sleeprestricted subjects who had no alcohol.

Driving after drinking is commonplace during college, as up to $34 \%$ of students reported driving after drinking within the last 30 days. $^{75}$ The combination of sleep deprivation and drinking may be especially common at the end of the semester, when sleep-deprived students celebrate the end of exams with drinks before driving home for the holiday break. The dangerous combination of sleep loss and alcohol could impair driving performance even in students who are not legally intoxicated.

\section{Mood effects}

Depression and sleep are interrelated. A cardinal feature of depression is disturbed sleep. ${ }^{76,77}$ Depression is common during the college years: $14.8 \%$ of students report a diagnosis of depression and an estimated $11 \%$ have suicidal ideation. ${ }^{78}$ Insufficient sleep can increase depressive symptoms. In a study of female college students, sleep debt of 2 hours per night and/or a bedtime after 2 am was associated with greater depressive symptoms. ${ }^{79}$ Irregular sleep schedules have been associated with greater depressive symptoms. Prolonged sleep latency was associated with loss of pleasure, punishment feelings, and self-dislike. ${ }^{80}$ Differences between sex were apparent, as women went to bed earlier, slept longer, had 
more nocturnal awakenings, and reported more depressive symptoms. However, when the sleep variable was removed by deleting the question, "Have you experienced changes in sleep?", no significant difference in sex persisted, suggesting the greater incidence of depression in college-aged women may be due in part to the greater number of reported sleep difficulties..$^{80,81}$

Improving sleep may improve depressive symptoms. Cognitive behavioral therapy for insomnia (CBT-I) administered via email to college students with poor sleep quality produced greater improvement in depressive symptoms than did an intervention focused on mood and stress reduction. ${ }^{67}$ A study on college students without reported sleepiness or depression found that sleep extension significantly improved scores on the Profile of Mood States. ${ }^{82}$ Increased total sleep in teenagers has also been shown to improve mood. When school start time was delayed by 30 minutes, fewer students rated themselves as "at least somewhat unhappy or depressed". ${ }^{83}$ As sleep may be a modifiable risk factor for depression, further research is needed on ways to improve sleep and sleep quality in depressed subjects.

Complex relationships exist between suicide, mood disorders, and sleep. Insomnia may be a risk factor for suicidal ideation, suicide attempts, and death by suicide. ${ }^{84}$ Conflicting results have been reported on whether both insomnia and nightmares increase the risk of suicidal ideation. ${ }^{85,86} \mathrm{~A}$ confounder is that post-traumatic stress disorder (PTSD) may account for these associations. A study among college students found that insomnia and nightmares were independently associated with suicidal ideation. However, after depression, anxiety, and PTSD were taken into account, nightmares, but not insomnia, retained an association with suicidal ideation. The presence of nightmares in a student with depression may be a warning sign of increased risk for suicidal ideation that warrants further evaluation. ${ }^{87}$

\section{Potential interventions}

While sleep deprivation, irregular sleep schedules and sleepiness are highly prevalent among college students, little information is available on effective ways for schools to successfully disseminate information on the importance of sleep and to potentially improve the sleep of their students. In general, the few programs that have been tried are expensive, time consuming, and available for only a limited number of students. A recent review of sleep education programs for children and adolescents found only twelve studies, of which four were available only as abstracts. ${ }^{81}$

\section{Educational programs}

Improved sleep hygiene, which is widely believed to be beneficial, has been the focus of most educational programs on sleep, although there is little published support. An American Academy of Sleep Medicine Practice Parameter concluded in 1999 that insufficient evidence exists to recommend sleep hygiene as a single therapy or in combination with other treatments. ${ }^{88}$ A study evaluating sleep hygiene awareness and sleep hygiene practice found only a weak association between knowledge and practice. However, good sleep hygiene practice was strongly correlated with good sleep quality. ${ }^{35}$ Adequate sleep knowledge does not necessarily translate into practice. Many sleep hygiene recommendations, such as a quiet environment and use of the bedroom only for sleep, may be challenging in college dormitories.

One educational campaign with a focus on sleep hygiene included a "Go to Bed" poster, a 2-page "Snooze letter", and sleep educational information in the school newspaper. An earlier bedtime, shorter sleep latency, longer sleep duration, and improved sleep quality, as measured by the Pittsburg Sleep Quality Index, was noted in 9\% of students. ${ }^{89}$ Although this intervention did not affect a large percentage of the student population, it was relatively inexpensive and did produce a measurable benefit (Table 3).

\section{Sleep courses}

In another study, a two-credit, 18-week course included group discussion, lectures, and self-evaluation. Topics included circadian rhythms, sleep hygiene, muscle relaxation, and public sleep education. ${ }^{90}$ Participants had improved sleep quality over the semester and women reported decreased nap time. However, despite this intensive intervention, only a limited effect on sleep patterns was observed.

The Sleep Treatment and Education Program (STEPS) consisted of a 30-minute oral presentation and handouts on various aspects of sleep, provided to students attending introductory psychology classes. ${ }^{91}$ Six weeks later, participants showed improved sleep quality and sleep

Table 3 Components in sleep educational programs

"Snooze Letter"
"Go to Bed" poster
Sleep education information in school newspaper
Two-credit course with discussion, lecture, self-assessment
30 -minute oral presentation
8 weeks of emailed PDF addressing sleep schedule, relaxation, etc
An extra credit online pre-test and self-education program
Note: Data from.


hygiene. These results may be more robust than suggested, as sleep quality and sleep behaviors typically worsen as the semester progresses; therefore, this intervention not only halted this deterioration, but resulted in improvement. ${ }^{92}$ Four supplementary sleep-learning modules, offered as extra credit, improved sleep knowledge and encouraged some sleep-related behavior changes, as $55 \%$ reported a change in their sleep hygiene as compared to $45 \%$ of control students $(P<0.01) .^{93}$ Students in the intervention reported specific behavior changes such as having a more "consistent wake time" versus a more general "trying to get more sleep" as indicated by the control students. However, all of these interventions are time consuming, involve only a select number of students, and may not be practicable on a large university scale.

\section{Electronic cognitive behavioral therapy}

More feasible options are under development. A modified form of cognitive behavioral therapy for insomnia (CBT-I) was emailed to students over an 8-week period. ${ }^{67}$ Each weekly email contained an attachment to address several aspects of sleep, such as stabilizing the circadian rhythm by anchoring wake time, relaxation techniques, and a protocol for self-administered sleep restriction. This was compared to an alternative program (Breathe), which was created to reduce depressive symptoms and improve coping skills for stress. Participants in the sleep program (Refresh) had improvement in sleep quality and a decrease in depressive symptoms. Although the study involved only a small number (19 and 15, respectively), results showed promise as an effective electronic program that could be widely accessible and economically feasible for colleges and universities.

\section{Class scheduling}

The amount of sleep that students obtain is often dictated by the first obligation of the day, typically their first class. This is one reason why students often sleep longer and later on a vacation or summer schedule. ${ }^{15}$ Therefore, class start times are an opportunity for intervention, but available information must be extrapolated from adolescent literature. A study at an independent college preparatory school showed increased sleep duration after a delay in school start time. The majority of students were boarders $(81.5 \%)$ with structured lights-out schedules ranging from $10.30-11.30 \mathrm{pm}{ }^{83}$ When school was started at $8.30 \mathrm{am}, 30$ minutes later than usual, sleep duration was increased by 45 minutes on school days. An unexpected effect was that bedtime shifted earlier by 15 minutes. Following the time change, fewer students reported daytime sleepiness (49.1\% to $20.0 \%$ ), sleepiness in class ( $85.1 \%$ to $60.5 \%)$, and falling asleep in class (38\% to $18 \%)$. A positive effect on mood was found, with a decrease in the Depressed Mood Scale. ${ }^{83}$ Students continued to have significant "oversleeping" on the weekend, by nearly 3 hours. A study of eighth graders (mean age 13.7 years) who had 1 hour of sleep extension for 5 days through delays in the school start time, documented improved attention and performance. ${ }^{94}$ This growing evidence from adolescents suggests that later school start times do increase total sleep duration, attention, and performance, but the data needs to be replicated in college students (Table 4).

\section{Naps}

Although not often considered as an intervention for sleep deprivation, daytime naps may offer a potential remedy that may also help academic performance. Interestingly, in light of how napping may improve certain memory tasks, high academic performers were more likely to nap than low academic performers (52\% vs $29 \%$, respectively). ${ }^{63}$ In a study of non-sleep-deprived subjects, deterioration in the performance of a visual perception task occurred during the day. ${ }^{95}$ Intervening naps of 60 or 90 minutes halted this deterioration, but only naps with both REM and slowwave sleep resulted in improvement compared to baseline. Sustained wakefulness can impair performance. In an episodic memory-encoding task (face and name recognition), significant deterioration at $6 \mathrm{pm}$ occurred in all subjects, except those who had had a 100-minute nap. In the nap group, not only was performance deterioration abated, but improvement was noted. ${ }^{27}$ Following training to recognize phonetically similar words, subjects showed an increase in accuracy, but 12 hours of sustained wakefulness reduced improvements by half. A nap prevented this decrement in performance. ${ }^{96,97}$ In short, naps may enhance certain cognitive and performance tasks, but further research is still needed in this important area.

Table 4 Potential interventions to reduce sleep deprivation and sleepiness

Extracurricular educational programs

Sleep courses

Scheduling classes at a later start time, eg, 10 am classes

Encouraging naps via educational programs or availability of "nap rooms" Public health outreach programs to students

Adequate evaluation and screening for sleep disorders 


\section{Conclusion}

The college years are a time of critical transition from adolescence to adulthood. For many individuals, this transition is associated with inadequate sleep and daytime sleepiness. Many factors contribute to this, including the students' own circadian physiology. Class times are often scheduled without consideration of young adults' circadian patterns. Inadequate sleep hygiene is common, as students often use technology and substances that compromise sleep quality and quantity. This chronic sleep deprivation may impair academic performance, mood regulation, and driving safety. Students who attain sufficient sleep may still struggle with sleepiness due to sleep disorders.

Further research is needed to not only determine how to best educate students about the importance of sleep and the consequences of sleep deprivation, but also how to translate this knowledge into practice. Electronic or web-based interventions may be economically feasible and attractive to an electronically savvy demographic. Universities and colleges need to understand, acknowledge, and publicize that policies and class schedules may have substantial impacts on the sleep, learning, and health of their students. Investigation of new approaches to promote good sleep and sleep habits could have significant public health impact and should be prioritized.

\section{Disclosure}

The authors report no conflicts of interest in this work.

\section{References}

1. Oginska H, Pokorski J. Fatigue and mood correlates of sleep length in three age-social goups: school children, students, and employees. Chronobiol Int. 2006;23(6):1317-1328.

2. American College Health Association. American College Health Association: National College Health Assessment II Reference Group Executive Summary Spring 2012. Hanover, MD: American College Health Association; 2012. Available from: http://www.acha-ncha. org/docs/ACHA-NCHA-II_ReferenceGroup_ExecutiveSummary_ Spring2012.pdf. Accessed February 20, 2014.

3. American Academcy of Sleep Medicine. International Classification of Sleep Disorders, 2nd ed: Diagnostic and Coding Manual. Westchester, IL: American Academy of Sleep Medicine; 2005.

4. Kryger MH, Roth T, Dement WC, editors. Principles and Practice of Sleep Medicine. St Louis, MO: Elsevier BV; 2005.

5. Wehr TA, Moul DE, Barbato G, et al. Conservation of photoperiodresponsive mechanisms in humans. Am J Physiol. 1993;265(4 Pt 2): R846-R857.

6. Van Dongen HP, Maislin G, Mullington JM, Dinges DF. The cumulative cost of additional wakefulness: dose-response effects on neurobehavioral functions and sleep physiology from chronic sleep restriction and total sleep deprivation. Sleep. 2003;26(2):117-126.

7. Lund HG, Reider BD, Whiting AB, Prichard JR. Sleep patterns and predictors of disturbed sleep in a large population of college students. J Adolesc Health. 2010;46(2):124-132.

8. Bachman L, Bachman C. Student perceptions of academic workload in architectural education. J Archit Plan Res. 2006;23(4):271-304.
9. Hershner S. College students' sleep habits and GPA. Sleep. 2011;34(Abstract Supplement):A102.

10. American College Health Association. American College Health Association: National College Health Assessment II Reference Group Executive Summary Fall 2011. Hanover, MD: American College Health Association; 2011. Available from: http://www.acha-ncha.org/docs/ ACHA-NCHA-II_ReferenceGroup_ExecutiveSummary_Fall2011.pdf. Accessed February 20, 2014.

11. Borbély AA. A two process model of sleep regulation. Hum Neurobiol. 1982;1(3):195-204.

12. Jenni OG, Carskadon MA. Sleep behavior and sleep regulation from infancy through adolescence: normative aspects. Sleep Med Clin. 2007;2(3):321-329.

13. Khaylis A, Trockel M, Taylor CB. Binge drinking in women at risk for developing eating disorders. Int J Eat Disorder. 2009;42(5):409-414.

14. Carskadon MA, Vieira C, Acebo C. Association between puberty and delayed phase preference. Sleep. 1993;16(3):258-262.

15. Crowley SJ, Acebo C, Carskadon MA. Sleep, circadian rhythms, and delayed phase in adolescence. Sleep Med. 2007;8(6):602-612.

16. Carskadon MA, Acebo C, Arnedt JT. Failure to identify pubertallymediated melatonin sensitivity to light in adolescents. Sleep. 2002;25: A191.

17. Hansen M, Janssen I, Schiff A, Zee PC, Dubocovich ML. The impact of school daily schedule on adolescent sleep. Pediatrics. 2005;115(6):1555-1561.

18. Roenneberg T, Wirz-Justice A, Merrow M. Life between clocks: daily temporal patterns of human chronotypes. J Biol Rhythm. 2003;18(1):80-90.

19. Thorleifsdottir B, Björnsson JK, Benediktsdottir B, Gislason T, Kristbjarnarson H. Sleep and sleep habits from childhood to young adulthood over a 10-year period. J Psychosom Res. 2002;53(1): 529-537.

20. Curcio G, Ferrara M, De Gennaro L. Sleep loss, learning capacity and academic performance. Sleep Med Rev. 2006;10(5):323-337.

21. Rauchs G, Desgranges B, Foret J, Eustache F. The relationships between memory systems and sleep stages. J Sleep Res. 2005;14(2):123-140.

22. Karni A, Tanne D, Rubenstein BS, Askenasy JJ, Sagi D. Dependence on REM sleep of overnight improvement of a perceptual skill. Science. 1994;265(5172):679-682.

23. Amlander CJ, Fuller PM, editors. Basics of Sleep Guide. 2nd ed. Westchester, IL: Sleep Research Society; 2005.

24. Walker MP, Brakefield T, Morgan A, Hobson JA, Stickgold R. Practice with sleep makes perfect: sleep-dependent motor skill learning. Neuron. 2002;35(1):205-211.

25. Smith C, MacNeill C. Impaired motor memory for a pursuit rotor task following Stage 2 sleep loss in college students. J Sleep Res. 1994;3(4):206-213.

26. Stickgold R, James L, Hobson JA. Visual discrimination learning requires sleep after training. Nat Neurosci. 2000;3(12):1237-1238.

27. Mander BA, Santhanam S, Saletin JM, Walker MP. Wake deterioration and sleep restoration of human learning. Curr Biol. 2011;21(5): R183-R184.

28. Pilcher JJ, Walters AS. How sleep deprivation affects psychological variables related to college students' cognitive performance. J Am Coll Health. 1997;46(3):121-126.

29. Randazzo AC, Muehlbach MJ, Schweitzer PK, Walsh JK. Cognitive function following acute sleep restriction in children ages 10-14. Sleep. 1998;21(8):861-868.

30. Carskadon MA, Harvey K, Dement WC. Sleep loss in young adolescents. Sleep. 1981;4(3):299-312.

31. Huber R, Ghilardi MF, Massimini M, Tononi G. Local sleep and learning. Nature. 2004;430(6995):78-81.

32. Briere ME, Forest G, Lussier I, Godbout R. Implicit verbal recall correlates positively with EEG sleep spindle activity. Sleep. 2000; 23(Suppl 2):A219.

33. De Koninck J, Lorrain D, Christ G, Proulx G, Coulombe D. Intensive language learning and increases in rapid eye movement sleep: evidence of a performance factor. Int J Psychophysiol. 1989;8(1):43-47. 
34. Stepanski EJ, Wyatt JK. Use of sleep hygiene in the treatment of insomnia. Sleep Med Rev. 2003;7(3):215-225.

35. Brown FC, Buboltz WC Jr, Soper B. Relationship of sleep hygiene awareness, sleep hygiene practices, and sleep quality in university students. Behav Med. 2002;28(1):33-38.

36. Task Force of the National Advisory Council on Alcohol Abuse and Alcoholism. A call to action: Changing the culture of drinking at US colleges. Bethesda, MD: National Institute on Alcohol Abuse and Alcoholism; 2002. NIH Publication No 02-5010. Available at: http:/ www.collegedrinkingprevention.gov/media/taskforcereport.pdf. Accessed August 8, 2013.

37. O'Malley PM, Johnston LD. Epidemiology of alcohol and other drug use among American college students. J Stud Alcohol Suppl. 2002;(14):23-39.

38. Taylor DJ, Bramoweth AD. Patterns and consequences of inadequate sleep in college students: substance use and motor vehicle accidents. J Adolesc Health. 2010;46(6):610-612.

39. Young T, Skatrud J, Peppard PE. Risk factors for obstructive sleep apnea in adults. $J$ Am Med Assoc. 2004;291(16):2013-2016.

40. Walsh JK, Muehlbach MJ, Humm TM, Dickins QS, Sugerman JL, Schweitzer PK. Effect of caffeine on physiological sleep tendency and ability to sustain wakefulness at night. Psychopharmacology. 1990;101(2):271-273.

41. O’Brien MC, McCoy TP, Rhodes SD, Wagoner A, Wolfson M. Caffeinated cocktails: energy drink consumption, high-risk drinking, and alcohol-related consequences among college students. Acad Emerg Med. 2008;15(5):453-460.

42. Malinauskas BM, Aeby VG, Overton RF, Carpenter-Aeby T, Barber-Heidal K. A survey of energy drink consumption patterns among college students. Nutr J. 2007;6:35.

43. Arria AM, Caldeira KM, Kasperski SJ, et al. Increased alcohol consumption, nonmedical prescription drug use, and illicit drug use are associated with energy drink consumption among college students J Addict Med. 2010;4(2):74-80.

44. Arria AM. Compromised sleep quality and low GPA among college students who use prescription stimulants nonmedically. Sleep Med. 2011;12(6):536-537.

45. Johnston LD, O'Malley PM, Bachman JG. Monitoring the Future: National Survey Results on Drug Use, 1975-2002. Volume II: College Students and Adults Ages 19-40. Washington, DC: US Department of Health and Human Services; 2002.

46. McCabe SE, Knight JR, Teter CJ, Wechser H. Non-medical use of prescription stimulants among US college students: prevalence and correlates from a national survey. Addiction. 2005;100(1): 96-106.

47. Clegg-Kraynok MM, McBean AL, Montgomery-Downs HE. Sleep quality and characteristics of college students who use prescription psychostimulants nonmedically. Sleep Med. 2011;12(6):598-602.

48. DuPaul GJ, Weyandt LL, O’Dell SM, Varejao M. College students with ADHD current status and future directions. J Atten Disord. 2009;13(3):234-250.

49. National Sleep Foundation. Sleep in America: Technology Use and Sleep. Arlington, VA: National Sleep Foundation; 2011. Available at: http://sleepfoundation.org/sites/default/files/sleepinamericapoll/ SIAP_2011_Summary_of_Findings.pdf. Accessed June 6, 2014.

50. Thomée S, Eklöf M, Gustafsson E, Nilsson R, Hagberg M. Prevalence of perceived stress, symptoms of depression and sleep disturbances in relation to information and communication technology (ICT) use among young adults - an explorative prospective study. Comput Human Behav. 2007;23(3):1300-1321.

51. Dworak M, Schierl T, Bruns T, Strüder HK. Impact of singular excessive computer game and television exposure on sleep patterns and memory performance of school-aged children. Pediatrics. 2007;120(5): 978-985.

52. Mathiak K, Weber R. Toward brain correlates of natural behavior: fMRI during violent video games. Hum Brain Mapp. 2006;27(12): 948-956.
53. Zeitzer JM, Dijk DJ, Kronauer RE, Brown EN, Czeisler CA Sensitivity of the human circadian pacemaker to nocturnal light: melatonin phase resetting and suppression. $J$ Physiol. 2000;526 Pt 3:695-702.

54. Wood B, Rea MS, Plitnick B, Figueiro MG. Light level and duration of exposure determine the impact of self-luminous tablets on melatonin suppression. Appl Ergon. 2013;44(2):237-240.

55. Louzada F, Inacio AM, Souza FHM, Moreno CRC. Exposure to light versus way of life: effects on sleep patterns of a teenager - case report. Chronobiol Int. 2004;21(3):497-499.

56. Teixeira L, Lowden A, Luz AA, et al. Exposure to bright light during evening class hours increases alertness among working college students. Sleep Med. 2013;14(1):91-97.

57. Gaultney JF. The prevalence of sleep disorders in college students: impact on academic performance. J Am Coll Health. 2010;59(2):91-97.

58. Chervin RD. Sleepiness, fatigue, tiredness, and lack of energy in obstructive sleep apnea. Chest. 2000;118(2):372-379.

59. Patel M, Tran D, Chakrabarti A, Vasquez A, Gilbert P, Davidson T. Prevalence of snoring in college students. JAm Coll Health. 2008;57(1): 45-52.

60. Trockel MT, Barnes MD, Egget DL. Health-related variables and academic performance among first-year college students: implications for sleep and other behaviors. J Am Coll Health. 2000;49(3): $125-131$.

61. Betts JR, Morell D. The determinants of undergraduate grade point average: the relative importance of family background, high school resources, and peer group effects. J Hum Resour. 1999;34(2):268-293.

62. Kelly WE, Kelley KE, Clanton RC. The relationship between sleep length and grade-point average among college students. Coll Stud J. 2001;35(1):84-86.

63. Eliasson AH, Lettieri CJ, Eliasson AH. Early to bed, early to rise! Sleep habits and academic performance in college students. Sleep Breath. 2010;14(1):71-75.

64. Medeiros AL. The relationship between sleep-wake cycle and academic performance in medical students. Biol Rhythm Res. 2001;32(2): 263-270.

65. Ficker JH, Wiest GH, Lehnert G, Meyer M, Hahn EG. Are snoring medical students at risk of failing their exams? Sleep. 1999;22(2): 205-209.

66. Alchanatis M, Zias N, Deligiorgis N, Amfilochiou A, Dionellis G, Orphanidou D. Sleep apnea-related cognitive deficits and intelligence: an implication of cognitive reserve theory. J Sleep Res. 2005;14(1):69-75.

67. Trockel M, Manber R, Chang V, Thurston A, Taylor CB. An e-mail delivered CBT for sleep-health program for college students: effects on sleep quality and depression symptoms. J Clin Sleep Med. 2011;7(3): 273-278.

68. Lack LC. Delayed sleep and sleep loss in university students. J Am Coll Health. 1986;35(3):105-110.

69. Brown FC, Soper B, Buboltz WC Jr. Prevalence of delayed sleep phase syndrome in university students. Coll Stud J. 2001;35(3):472.

70. Lindsay GA, Hanks WA, Hurley RD, Dane S. Descriptive epidemiology of dozing and driving in a college student population. J Am Coll Health. 1999;47(4):157-162.

71. Dawson D, Reid K. Fatigue, alcohol and performance impairment. Nature. 1997;388(6639):235.

72. International Center For Alcohol Policies. Blood Alcohol Concentration (BAC) Limits Worldwide. Washington, DC: International Center For Alcohol Policies; 2013. Available at: http://www.icap.org/PolicyIssues/ DrinkingandDriving. Accessed April 30, 2013.

73. Arnedt JT, Wilde GJ, Munt PW, MacLean AW. How do prolonged wakefulness and alcohol compare in the decrements they produce on a simulated driving task? Accid Anal Prev. 2001;33(3):337-344.

74. Vakulin A, Baulk SD, Catcheside PG, et al. Effects of moderate sleep deprivation and low-dose alcohol on driving simulator performance and perception in young men. Sleep. 2007;30(10): $1327-1333$. 
75. American College Health Association. American College Health Association National College Health Assessment Spring 2006 Reference Group data report (abridged). J Am Coll Health. 2007;55(4):195-206.

76. Buysse DJ, Angst J, Gamma A, Ajdacic V, Eich D, Rössler W. Prevalence, course, and comorbidity of insomnia and depression in young adults. Sleep. 2008;31(4):473-480.

77. Ford DE, Kamerow DB. Epidemiologic study of sleep disturbances and psychiatric disorders. An opportunity for prevention? JAMA. 1989;262(11):1479-1484.

78. Garlow SJ, Rosenberg J, Moore JD, et al. Depression, desperation, and suicidal ideation in college students: results from the American Foundation for Suicide Prevention College Screening Project at Emory University. Depress Anxiety. 2008;25(6):482-488.

79. Regestein Q, Natarajan V, Pavlova M, Kawasaki S, Gleason R, Koff E. Sleep debt and depression in female college students. Psychiatry Res. 2010;176(1):34-39.

80. Brooks PR, Giigenti AA, Milles MJ. Sleep patterns and symptoms of depression in college students. Coll Stud J. 2009;43(2):464-472.

81. Blunden SL, Chapman J, Rigney GA. Are sleep education programs successful? The case for improved and consistent research efforts. Sleep Med Rev. 2012;16(4):355-370.

82. Kamdar BB, Kaplan KA, Kezirian EJ, Dement WC. The impact of extended sleep on daytime alertness, vigilance, and mood. Sleep Med. 2004;5(5):441-448.

83. Owens JA, Belon K, Moss P. Impact of delaying school start time on adolescent sleep, mood, and behavior. Arch Pediatr Adolesc Med. 2010;164(7):608-614.

84. Fujino Y, Mizoue T, Tokui N, Yoshimura T. Prospective cohort study of stress, life satisfaction, self-rated health, insomnia, and suicide death in Japan. Suicide Life Threat Behav. 2005;35(2):227-237.

85. Cukrowicz KC, Otamendi A, Pinto JV, Bernert RA, Krakow B, Joiner TE Jr. The impact of insomnia and sleep disturbances on depression and suicidality. Dreaming. 2006;16(1):1-10.
86. Sjostrom N, Waern M, Hetta J. Nightmares and sleep disturbances in relation to suicidality in suicide attempters. Sleep. 2007;30(1):91-95.

87. Nadorff MR, Nazem S, Fiske A. Insomnia symptoms, nightmares, and suicidal ideation in a college student sample. Sleep. 2011;34(1): 93-98.

88. Chesson AL, Anderson WM, Littner M, et al. Practice parameters for the nonpharmacologic treatment of chronic insomnia. Sleep. 1999;22(8):1128-1133.

89. Orzech KM, Salafsky DB, Hamilton LA. The state of sleep among college students at a large public university. J Am Coll Health. 2011;59(7):612-619.

90. Tsai LL, Li SP. Sleep education in college: a preliminary study. Percept Mot Skills. 2004;99(3):837-848.

91. Brown FC, Buboltz WC Jr, Soper B. Development and evaluation of the Sleep Treatment and Education Program for Students (STEPS). J Am Coll Health. 2006;54(4):231-237.

92. Hawkins J, Shaw P. Self-reported sleep quality in college students: a repeated measures approach. Sleep. 1992;15(6):545-549.

93. Quan SF, Anderson JL, Hodge GK. Use of a supplementary internet based education program improves sleep literacy in college psychology students. J Clin Sleep Med. 2013;9(2):155-160.

94. Lufi D, Tzischinsky O, Hadar S. Delaying school starting time by one hour: some effects on attention levels in adolescents. J Clin Sleep Med. 2011;7(2):137-143.

95. Mednick S, Nakayama K, Stickgold R. Sleep-dependent learning: a nap is as good as a night. Nat Neurosci. 2003;6(7):697-698.

96. Fenn KM, Nusbaum HC, Margoliash D. Consolidation during sleep of perceptual learning of spoken language. Nature. 2003; 425(6958):614-616.

97. Walker MP, Stickgold R. Sleep-dependent learning and memory consolidation. Neuron. 2004;44(1):121-133.
Nature and Science of Sleep

\section{Publish your work in this journal}

Nature and Science of Sleep is an international, peer-reviewed, open access journal covering all aspects of sleep science and sleep medicine, including the neurophysiology and functions of sleep, the genetics of sleep, sleep and society, biological rhythms, dreaming, sleep disorders and therapy, and strategies to optimize healthy sleep. The journal welcomes

\section{Dovepress}

original research, clinical \& epidemiological studies, reviews \& evaluations, case reports and extended reports. The manuscript management system is completely online and includes a very quick and fair peerreview system, which is all easy to use. Visit http://www.dovepress.com/ testimonials.php to read real quotes from published authors. 